\title{
Neuronal Protease-Activated Receptor 1 Drives Synaptic Retrograde Signaling Mediated by the Endocannabinoid 2-Arachidonoylglycerol
}

\author{
Yuki Hashimotodani, ${ }^{1}$ Takako Ohno-Shosaku, ${ }^{2}$ Maya Yamazaki, ${ }^{3}$ Kenji Sakimura, ${ }^{3}$ and Masanobu Kano ${ }^{1}$ \\ ${ }^{1}$ Department of Neurophysiology, Graduate School of Medicine, The University of Tokyo, Bunkyo-ku, Tokyo 113-0033, Japan, ${ }^{2}$ Division of Health Science, \\ Graduate School of Medical Science, Kanazawa University, Kanazawa 920-0942, Japan, and ${ }^{3}$ Department of Cellular Neurobiology, Brain Research Institute, \\ Niigata University, Niigata 951-8585, Japan
}

Protease-activated receptor 1 (PAR1) is a member of the G-protein coupled receptors that are proteolytically activated by serine proteases. Recent studies suggest a definite contribution of PAR1 to brain functions, including learning and memory. However, cellular mechanisms by which PAR1 activation influences neuronal activity are not well understood. Here we show that PAR1 activation drives retrograde endocannabinoid signaling and thereby regulates synaptic transmission. In cultured hippocampal neurons from rat, PAR1 activation by thrombin or PAR1-specific peptide agonists transiently suppressed inhibitory transmission at cannabinoid-sensitive, but not cannabinoid-insensitive, synapses. The PAR1-induced suppression of synaptic transmission was accompanied by an increase in paired-pulse ratio, and was blocked by a cannabinoid $\mathrm{CB}_{1}$ receptor antagonist. The PAR1-induced suppression was blocked by pharmacological inhibition of postsynaptic diacylglycerol lipase (DGL), a key enzyme for biosynthesis of the major endocannabinoid 2-arachidonoylglycerol (2-AG), and was absent in knock-out mice lacking the $\alpha$ isoform of DGL. The PAR1-induced IPSC suppression remained intact under the blockade of metabotropic glutamate receptors and was largely resistant to the treatment that blocked $\mathrm{Ca}^{2+}$ elevation in glial cells following PAR1 activation, which excludes the major contribution of glial PAR1 in IPSC suppression. We conclude that activation of neuronal PAR1 triggers retrograde signaling mediated by $2-\mathrm{AG}$, which activates presynaptic $\mathrm{CB}_{1}$ receptors and suppresses transmitter release at hippocampal inhibitory synapses.

\section{Introduction}

Protease-activated receptors (PARs) are members of seven transmembrane domain G-protein-coupled receptors and consist of four subtypes (PAR1-PAR4) (Ossovskaya and Bunnett, 2004). Activation of PARs is initiated by a unique mechanism that protease cleaves a specific site within extracellular $\mathrm{N}$ terminus region of the receptor. This cleavage reveals a new $\mathrm{N}$ terminus, which acts as a tethered ligand and then binds and activates the receptor. PARs are abundantly expressed in the brain and have been shown to play various roles in pathophysiological conditions such as neurogenic inflammation, neurodegeneration, and neuroprotection (Ossovskaya and Bunnett, 2004; Luo et al., 2007).

PARs may also contribute to neural functions under physiological conditions. PAR1-deficient mice show defects in passiveavoidance task, cued fear conditioning (Almonte et al., 2007),

Received Nov. 16, 2010; revised Dec. 26, 2010; accepted Dec. 29, 2010.

This work was supported by Grants-in-Aid for Scientific Research (21220006 and 21650094 to M.K., 18-08582 to Y.H., and 20021014 and 20500357 to T.O.S.), the Strategic Research Program for Brain Sciences (Development of Biomarker Candidates for Social Behavior), and Global COE program (Integrative Life Science Based on the Study of Biosignaling Mechanisms) from Ministry of Education, Culture, Sports, Science, and Technology, Japan. We thank A. Koseki for technical assistance, and H. Mizoguchi and K. Yamada for the generous gift of PAR1 knock-out mice.

Correspondence should be addressed to Masanobu Kano, Department of Neurophysiology, Graduate School of Medicine, The University of Tokyo, 7-3-1 Hongo, Bunkyo-ku, Tokyo 113-0033, Japan. E-mail: mkano-tky@m.u-tokyo.ac.jp.

DOI:10.1523/JNEUROSCI.6000-10.2011

Copyright $\odot 2011$ the authors $\quad 0270-6474 / 11 / 313104-06 \$ 15.00 / 0$ and nicotine-induced place preference (Nagai et al., 2006). At cellular levels, PAR1 activation influences synaptic transmission. PAR1 activation potentiated NMDA receptor currents (Gingrich et al., 2000; Mannaioni et al., 2008), induced long-term potentiation (LTP) of excitatory transmission (Maggio et al., 2008) in CA1 pyramidal neurons of hippocampal slices, and enhanced spontaneous release of glutamate onto substantia gelatinosa neurons in spinal cord slices (Fujita et al., 2009). As to the mechanisms, several studies have demonstrated that PAR agonists activate astrocytic PAR1, rather than neuronal PAR1, and induce glutamate release from astrocytes, thereby activating neuronal NMDA receptors in hippocampal acute slices (Lee et al., 2007; Mannaioni et al., 2008; Shigetomi et al., 2008) and hippocampal coculture preparations (Lee et al., 2007). In situ hybridization studies suggest that PAR1 is expressed in both astrocytes and neurons, including hippocampal pyramidal and granule cells (Weinstein et al., 1995; Niclou et al., 1998). Our knowledge of the roles of neuronal PAR1 in the regulation of synaptic transmission is, however, rather limited, especially at inhibitory synapses.

Endocannabinoid-mediated retrograde modulation of synaptic transmission plays important roles in various brain functions (Heifets and Castillo, 2009; Kano et al., 2009). Endocannabinoids are released from postsynaptic neurons and retrogradely activate presynaptic $\mathrm{CB}_{1}$ receptors, which leads to suppression of transmitter release. Endocannabinoid release is induced by postsynaptic depolarization (Kreitzer and Regehr, 2001; Ohno-Shosaku et al., 2001; 
Wilson and Nicoll, 2001) and/or activation of several types of $\mathrm{G}_{\mathrm{q} / 11^{-}}$ coupled receptors, including group I metabotropic glutamate receptors (I-mGluRs) (Maejima et al., 2001). Activation of phospholipase $\mathrm{C} \beta$ (PLC $\beta$ ) through these receptors produces diacylglycerol (DG), which is then hydrolyzed by DG lipase $\alpha$ (DGL $\alpha)$ and yields the endocannabinoid 2-arachidonoylglycerol (2-AG) (Hashimotodani et al., 2005; Maejima et al., 2005; Gao et al., 2010; Tanimura et al., 2010). Importantly, PAR1 activates $\mathrm{G}_{\mathrm{q} / 11}$ protein and stimulates phosphoinositide hydrolysis via PLC $\beta$ (Ossovskaya and Bunnett, 2004; McLaughlin et al., 2005). Therefore, it is likely that PAR1 activation can drive endocannabinoid signaling. This possibility, however, has never been tested electrophysiologically. In the present study, we used cannabinoid-sensitive inhibitory synapses of cultured hippocampal neurons, and demonstrated for the first time that neuronal PAR1 activation can modulate the synaptic transmission through the endocannabinoid 2-AG signaling.

\section{Materials and Methods}

Cell culture. All experiments were performed according to the guidelines laid down by the animal welfare committees of the University of Tokyo, Kanazawa and Niigata Universities. Cultured hippocampal neurons were prepared from newborn Sprague Dawley rats, PAR1 knock-out mice (The Jackson Laboratory) (Connolly et al., 1996), DGL $\alpha$ knock-out mice (Tanimura et al., 2010), and their wild-type littermates, as described previously (Ohno-Shosaku et al., 2001). Male and female animals were used. Briefly, cells were mechanically dissociated from the hippocampi and plated either onto poly-L-ornithine-coated plastic dishes for electrophysiological experiments or low-fluorescence plastic films (Sumilon MS-92132; Sumitomo) for $\mathrm{Ca}^{2+}$ imaging. The cultures were kept at $36^{\circ} \mathrm{C}$ in $5 \% \mathrm{CO}_{2}$ for $12-15 \mathrm{~d}$ before use.

Electrophysiology. Double whole-cell recordings were performed from cultured hippocampal neurons using a patch-clamp amplifier (EPC10/2; HEKA Electronik). Each neuron of a pair was voltage clamped at $-80 \mathrm{mV}$ using a patch pipette (3-5 M $\Omega$ ) filled with the internal solution with the following compositions (in $\mathrm{mM}$ ): $130 \mathrm{~K}$-gluconate, $15 \mathrm{KCl}, 10 \mathrm{HEPES}, 0.2$ EGTA, $6 \mathrm{MgCl}_{2}, 5 \mathrm{Na}_{2} \mathrm{ATP}$, and $0.2 \mathrm{Na}_{2} \mathrm{GTP}$ (pH 7.3, adjusted with $\mathrm{KOH}$ ). For the experiments shown in Figure $3 E$, we used the internal solution with the following compositions for postsynaptic neurons (in mM): 109.6 (for pCa 6) or 121.8 (for pCa 9) K-gluconate, $15 \mathrm{KCl}, 10 \mathrm{HEPES}, 10 \mathrm{BAPTA}, 8.47$ (for pCa 6) or 0.0549 (for pCa 9) $\mathrm{CaCl}_{2}, 5 \mathrm{MgCl}_{2}, 5 \mathrm{Na}_{2} \mathrm{ATP}$, and 0.2 $\mathrm{Na}_{2} \mathrm{GTP}$ (pH 7.3, adjusted with KOH) (Hashimotodani et al., 2005). One neuron was stimulated by applying positive voltage pulses (to $0 \mathrm{mV}, 2 \mathrm{~ms}$ ) at 0.5 or $0.25 \mathrm{~Hz}$, and IPSCs were measured from the other neuron. The external solution contained the following (in mM): $140 \mathrm{NaCl}, 2.5 \mathrm{KCl}, 2 \mathrm{CaCl}_{2}, 1$ $\mathrm{MgCl}_{2}, 10$ HEPES, 10 glucose, and 1 kynurenic acid ( $\mathrm{pH} 7.3$, adjusted with $\mathrm{NaOH}$ ). The recording chamber was perfused with the external solution at a flow rate of $1-3 \mathrm{ml} / \mathrm{min}$. Our culture preparations contain cannabinoid-sensitive and -insensitive inhibitory neurons (OhnoShosaku et al., 2001). The cannabinoid sensitivity of IPSCs was determined by triggering depolarization-induced suppression of inhibition (DSI), a form of endocannabinoid-mediated short-term depression (Alger, 2002). We defined cannabinoid-sensitive and -insensitive IPSCs by DSI-positive ( $>30 \%$ of suppression) and DSI-negative ( $<10 \%$ of suppression) IPSCs, respectively. PAR1 activators (thrombin, TFLLR, SFLLRN) were locally applied for $1 \mathrm{~min}$ through a capillary tube $(250 \mu \mathrm{m}$ inner diameter) located near the recorded neurons using a perfusion valve controller (VC-6M; Warner Instruments). All experiments were performed at room temperature.

$\mathrm{Ca}^{2+}$ imaging. Hippocampal cultures on the films were incubated with $5 \mu \mathrm{M}$ fura-2 AM (Dojindo) at $36^{\circ} \mathrm{C}$ for $15 \mathrm{~min}$ and then transferred to a glass-based dish mounted in the recording chamber and perfused with the external solution (see Electrophysiology, above); $1 \mathrm{~mm}$ kynurenic acid was replaced with $0.1 \mu \mathrm{M}$ tetrodotoxin. Fluorescence signals for excitation of 340 and $380 \mathrm{~nm}$ were measured at $0.2 \mathrm{~Hz}$ by using an imaging system (Acquacosmos; Hamamatsu Photonics) mounted on an inverted microscope (IX70; Olympus).
Drugs. TFLLR-NH ${ }_{2}$, AM251, 3,5-dihydroxyphenylglycine (DHPG), 2-methyl-6-(phenylethynyl)pyridine (MPEP), LY367385, and thapsigargin were purchased from Tocris Bioscience. Thrombin, SFLLRN, and tetrahydrolipstatin (THL) were purchased from Sigma-Aldrich. LY367385 was dissolved in $\mathrm{NaOH}$-containing water as a stock solution. TFLLR, SFLLRN, thrombin, and DHPG were dissolved in water. All other drugs were dissolved in DMSO.

Data analysis. In each experiment, amplitudes of 10 consecutive IPSCs during application of receptor activators were averaged and normalized to the control values before application. Statistical significance was assessed by Student's $t$ test or Mann-Whitney $U$ test.

\section{Results}

\section{Activation of PAR1 induces IPSC suppression}

We first examined effects of PAR1 activation on hippocampal IPSC by using an endogenous PAR activator, thrombin, and two PAR1-selective peptide agonists, TFLLR and SFLLRN. If PAR1 triggers endocannabinoid release, cannabinoid-sensitive IPSCs (see Materials and Methods) would be influenced selectively. As expected, local application of thrombin transiently suppressed cannabinoid-sensitive IPSCs (DSI-positive) (Fig. 1A), but not cannabinoid-insensitive IPSCs (DSI-negative) (Fig. $1 B$ ). In the following experiments, we used only the cannabinoid-sensitive IPSCs. In most cases, suppression was recovered gradually from its peak even in the presence of thrombin. When thrombin application was repeated, the second application failed to suppress IPSCs (Fig. 1D,F), which can be explained by receptor desensitization (Kawabata et al., 1999). Similar suppressing effects on cannabinoid-sensitive IPSCs were observed with TFLLR (Fig. $1 C)$ and SFLLRN $(29.0 \pm 6.0 \%$ of control). When TFLLR was applied repeatedly, the second application failed to suppress IPSCs (Fig. 1E,F). When TFLLR and thrombin were applied sequentially, IPSCs were suppressed only at the first application regardless of the order (Fig. $1 G-I$ ), indicating the involvement of the same receptor. The involvement of PAR1 was further confirmed by the results showing that TFLLR-induced IPSC suppression was absent in PAR1 knock-out mice (Fig. $1 J-L$ ). The IPSC suppression induced by thrombin or TFLLR was accompanied by an increase in paired-pulse ratio (Fig. $1 M$ ), which is generally used as a marker of presynaptic change. These results indicate that PAR1 activation induces presynaptic suppression of inhibitory transmission at cannabinoid-sensitive synapses.

\section{Endocannabinoid signaling is involved in PAR1-mediated IPSC suppression}

We next examined whether the PAR1-driven suppression of IPSCs is mediated by endocannabinoids. The IPSC suppressions induced by thrombin and TFLLR were both abolished by the treatment with AM251 (Fig. 2A,B,E,F). Recent studies have revealed that 2-AG produced by DGL $\alpha$ mediates retrograde synaptic suppression (Gao et al., 2010; Tanimura et al., 2010). Therefore, by using pharmacological and genetic tools, we tested whether the PAR1-driven suppression of IPSCs is dependent on DGL $\alpha$. Treatment with a DGL inhibitor, THL, completely blocked both thrombin and TFLLR-induced IPSC suppression (Fig. 2C-F). In hippocampal neurons prepared from DGL $\alpha$ knock-out mice, TFLLR failed to suppress IPSCs (Fig. 2G-I). From these results, we conclude that PAR1 activation leads to production and release of 2-AG in a DGL $\alpha$-dependent manner and induces suppression of GABA release through activation of presynaptic $\mathrm{CB}_{1}$ receptors. 


\section{2-AG is produced and released from postsynaptic neurons upon \\ PAR1 activation}

We then examined whether 2-AG was produced within postsynaptic neurons upon PAR1 activation, by applying the DGL inhibitor THL to the postsynaptic neurons through patch pipettes. Effectiveness of postsynaptically applied THL was estimated by monitoring DHPG (I-mGluR agonist)induced and depolarization-induced IPSC suppressions (Fig. 2J), both of which were previously demonstrated to be blocked by bath-applied THL in our preparations (Hashimotodani et al., 2007b, 2008). When THL was applied postsynaptically, thrombinand TFLLR-induced IPSC suppressions were reduced by similar degrees to DHPG- and depolarization-induced suppressions (Fig. $2 J)$. These results clearly indicate that the IPSC suppression is mediated by $2-\mathrm{AG}$ that is produced and released from postsynaptic neurons upon PAR1 activation.

\section{Neuronal PAR1 is responsible for generation of endocannabinoid signaling}

A simple model for PAR1-driven 2-AG release is that PAR1 activation and 2-AG production occur in the same postsynaptic neuron. However, it is also possible that PAR1 activation and 2-AG production occur in separate cells. Recent studies have demonstrated that astrocytes are able to release several gliotransmitters, including glutamate, when cytosolic $\mathrm{Ca}^{2+}$ concentration is elevated (Perea et al., 2009). Therefore, it is possible that activation of astrocytic PAR1 causes $\mathrm{Ca}^{2+}$ elevation and thereby induces glutamate release, which then activates neuronal I-mGluRs (mGluR1 and/or mGluR5) and initiates 2-AG production through I-mGluR-PLC $\beta$-DGL $\alpha$ pathway within the postsynaptic neuron. To test this possibility, effects of combined treatment with the mGluR1 antagonist LY367385 and the mGluR5 antagonist MPEP on PAR1-driven IPSC suppression were examined. This treatment blocked the IPSC suppression induced by the I-mGluR agonist DHPG, but failed to block thrombin- and TFLLRinduced suppressions of IPSCs (Fig. 3A).

To test whether gliotransmitters other than glutamate are involved, we treated culture preparations with thapsigargin to deplete $\mathrm{Ca}^{2+}$ stores, which is expected to block $\mathrm{Ca}^{2+}$ elevation and gliotransmitter release (Mothet et al., 2005). We confirmed that $\mathrm{Ca}^{2+}$ transients triggered by TFLLR application were completely blocked in thapsigargin-treated astrocytes (Fig. $3 B, C$ ). This treatment attenuated the TFLLRinduced suppression of IPSCs, but left a
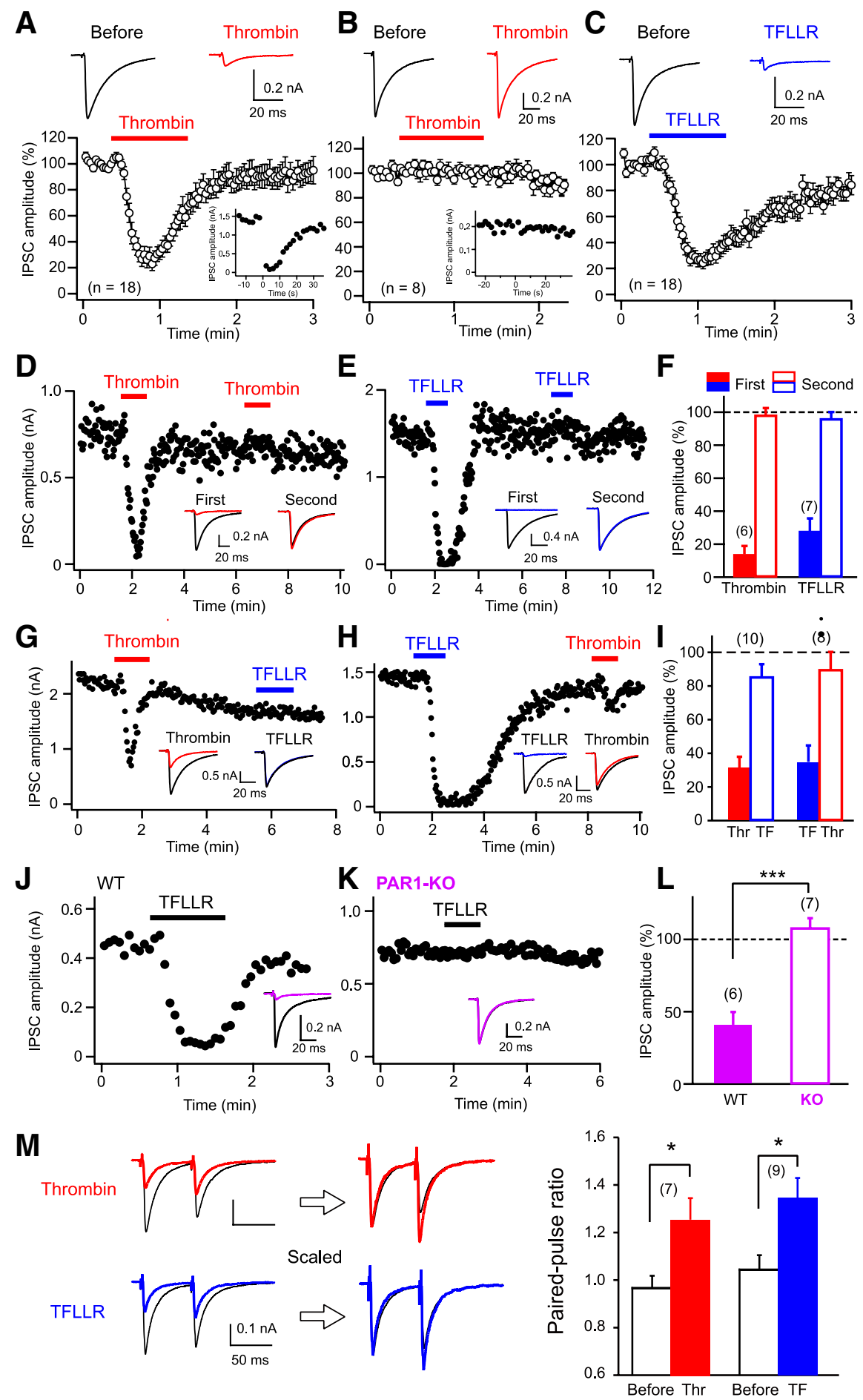

Figure 1. Thrombin and PAR1 agonists induce transient suppression of IPSCs. $\boldsymbol{A}-\boldsymbol{C}$, Top, Representative IPSC traces before (left) and during (right) application of thrombin $(1 \mathrm{U} / \mathrm{ml}$, red) or TFLLR (10 $\mu \mathrm{m}$, blue). Each trace is the average of five IPSCs. Bottom, Normalized IPSC time course during application of PAR1 activators. Data were obtained from cannabinoid-sensitive $(\boldsymbol{A}, \boldsymbol{C})$ and cannabinoid-insensitive $(\boldsymbol{B})$ IPSCS. Insets, Representative data showing positive $(\boldsymbol{A})$ and negative $(\boldsymbol{B})$ DSI responses. A depolarizing pulse $(5 \mathrm{~s}, 0 \mathrm{mV})$ was applied to the postsynaptic neuron at time $0 . \boldsymbol{D}-\boldsymbol{F}$, Representative experiments $(\boldsymbol{D}, \boldsymbol{E})$ and summary bar graph $(\boldsymbol{F})$ for the effects of repeated application of thrombin or TFLLR. Two IPSC traces acquired before (black) and during application of thrombin (red) or TFLLR (blue) are superimposed in each sample record in insets. G-I, Effects of sequential application of thrombin (Thr) and TFLLR (TF), illustrated as in D-F. J-L, Effects of TFLLR (10 $\mu \mathrm{M})$ on IPSCs in wild-type (WT) and PAR1-knock-out (KO) mice. Two IPSC traces acquired before (black) and during (pink) application of thrombin or TFLLRare superimposed in each sample record in insets. $\boldsymbol{M}$, Left, Examples of IPSC traces in response to paired stimuli (60 ms interval) before (black) and during application of thrombin (red) or TFLLR (blue). Right, Averaged data for the increase in paired-pulse ratio by thrombin and TFLLR. Numbers in parentheses represent the number of tested cells. ${ }^{*} p<0.05,{ }^{* * *} p<0.001$. All data are presented as mean \pm SEM. 
A

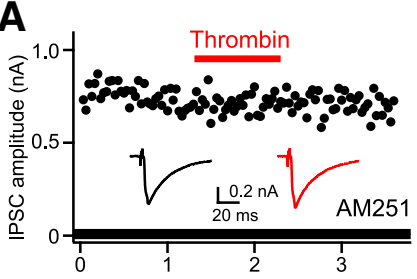

C

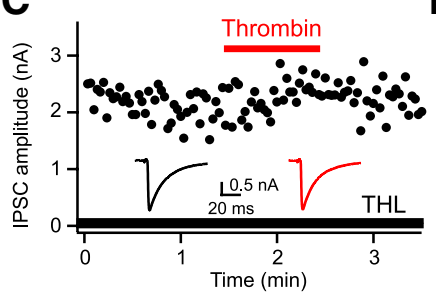

E

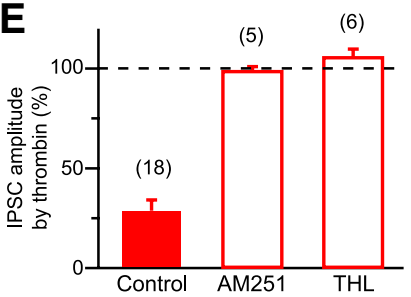

B

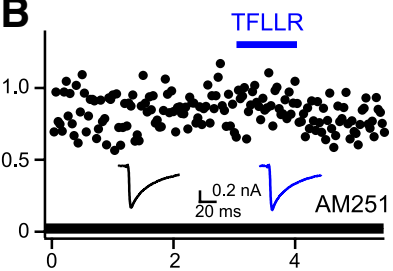

D

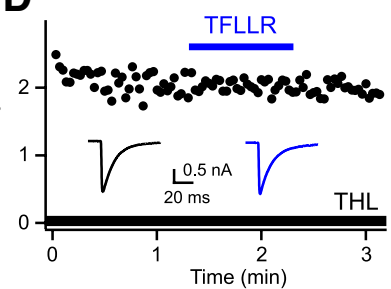

$\mathbf{F}$

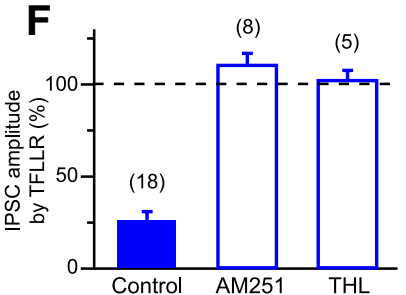

$H_{\text {DGLa-KO }}$
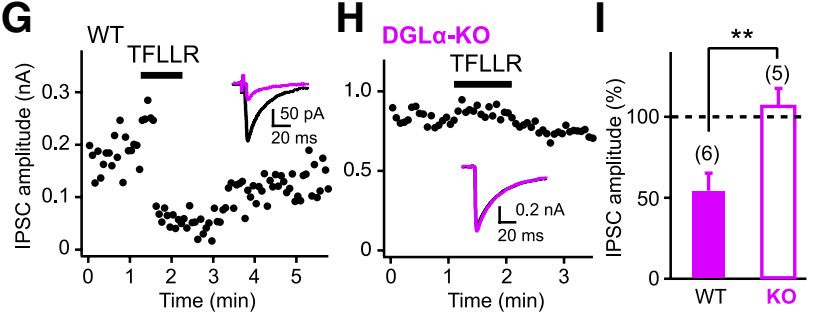

$\mathbf{J}$

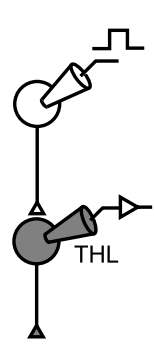

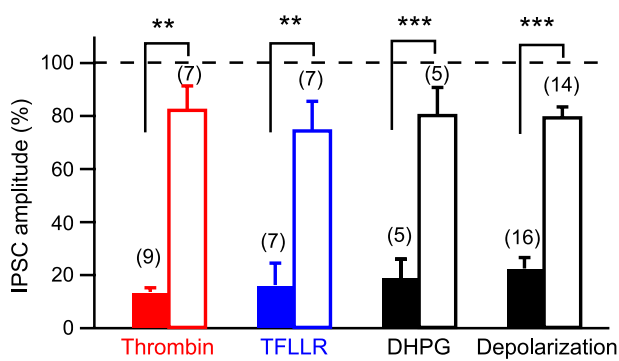

Thrombin TFLLR DHPG Depolarization

Figure 2. Involvement of endocannabinoid signaling in PAR1-induced IPSC suppression. $\boldsymbol{A}-\boldsymbol{D}$, Representative data showing effects of AM251 $(0.3 \mu \mathrm{m} ; \boldsymbol{A}, \boldsymbol{B})$ and THL ( $5 \mu \mathrm{m} ; \boldsymbol{C}, \boldsymbol{D})$ on IPSC suppression induced by thrombin $(1 \mathrm{U} / \mathrm{ml})$ or TFLLR $(10 \mu \mathrm{m})$. Representative IPSC traces acquired before (left) and during (right) application of thrombin or TFLLR are shown in insets. $\boldsymbol{E}, \boldsymbol{F}$, Summary graph showing normalized IPSC amplitudes during application of thrombin $(\boldsymbol{E})$ or TFLLR $(\boldsymbol{F})$ in the presence of AM251 and THL. $\mathbf{G}-\boldsymbol{I}$, TFLLR-induced IPSC suppression is absent in DGL $\alpha$-knock-out (KO) mice. Data are illustrated similarly to Figure 1J-L. J, Intracellular application of THL $(10 \mu \mathrm{M})$ to a postsynaptic neuron greatly reduced IPSC suppressions by thrombin $(1 \mathrm{U} / \mathrm{ml})$, TFLLR $(10 \mu \mathrm{m})$, DHPG $(20 \mu \mathrm{m})$, and postsynaptic depolarization $(5 \mathrm{~s})$ to the similar extents. Filled and open columns represent normalized IPSC amplitudes for control and THLinjected neurons. Numbers in parentheses represent the number of tested cells. WT, Wild-type. ${ }^{* *} p<0.01,{ }^{* * *} p<0.001$. All data are presented as mean \pm SEM.

large part of suppression intact (Fig. 3D). This thapsigargin-resistant component of IPSC suppression should be independent of gliotransmitters, and thus dependent on neuronal PAR1 rather than astrocytic PAR1. As to the thapsigargin-sensitive component, there are two possibilities. This component may be dependent on astrocytic PAR1 and mediated by gliotransmitters. Alternatively, this component may also be dependent on neuronal PAR1, but sensitive

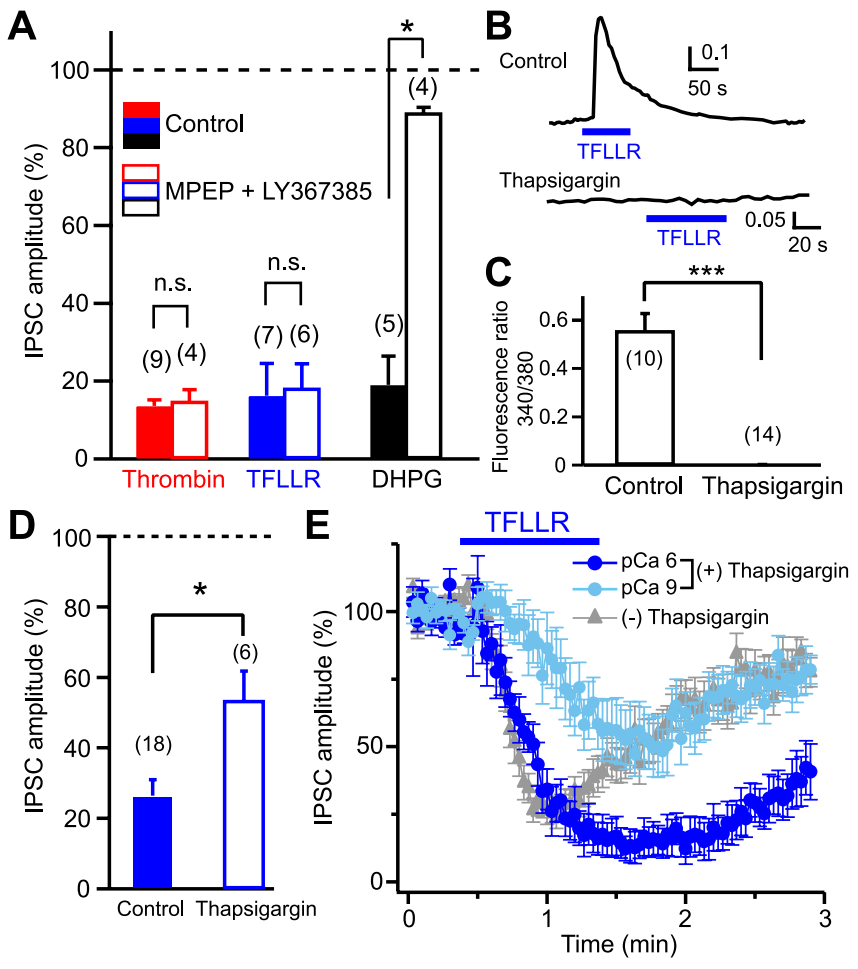

Figure 3. Neuronal PAR1, rather than glial PAR1, is responsible for generation of 2-AG signaling. $A$, Normalized IPSC amplitudes during application of thrombin ( $1 \mathrm{U} / \mathrm{ml}), \operatorname{TFLLR}(10 \mu \mathrm{M})$, and DHPG $(20 \mu \mathrm{m})$ in the presence (open columns) or absence (filled columns) of a mixture of MPEP $(5 \mu \mathrm{M})$ and LY367385 $(100 \mu \mathrm{M}) . \boldsymbol{B}$, $\boldsymbol{C}$, Representative data $(\boldsymbol{B})$ and summary graph $(\boldsymbol{C}$ showing complete suppression of TFLLR-induced $\mathrm{Ca}^{2+}$ elevation in glial cells by thapsigargin (1 $\mu \mathrm{M})$. D, Normalized IPSC amplitudes during application of TFLLR (10 $\mu \mathrm{M})$ after treatment with thapsigargin (1 $\mu \mathrm{M})$ for $1 \mathrm{~h}$ (open column). The control data without thapsigargin-treatment (filled column) (see Fig. 2F) are shown for comparison. E, TFLLR-induced IPSC suppression was dependent on postsynaptic $\mathrm{Ca}^{2+}$ concentration. After treatment with thapsigargin $(1 \mu \mathrm{m}, 1 \mathrm{~h})$, TFLLR $(10 \mu \mathrm{M})$ was applied to the postsynaptic neurons dialyzed with two different pipette solutions, pCa $6(n=7)$ and pCa $9(n=8)$. Results from nontreated neurons (Fig. 1C) were superimposed (gray triangles). Numbers in parentheses represent the number of tested cells. ${ }^{*} p<0.05 ;{ }^{* * *} p<0.001$. All data are presented as mean \pm SEM. n.S., Not significant.

to thapsigargin, because neuronal PAR1 activation induces local $\mathrm{Ca}^{2+}$ elevation, which can enhance 2-AG production. The endocannabinoid release driven by $\mathrm{G}_{\mathrm{q} / 11}$-coupled receptors such as I-mGluR and $M_{1} / M_{3}$ receptors has been demonstrated to be dependent on basal $\mathrm{Ca}^{2+}$ concentration and enhanced by postsynaptic $\mathrm{Ca}^{2+}$ elevation (Hashimotodani et al., 2007a). To examine the $\mathrm{Ca}^{2+}$ dependence of PAR1-driven 2-AG release, we dialyzed thapsigargintreated postsynaptic neurons with either pCa 6 or pCa 9 pipette solution (Hashimotodani et al., 2005). The TFLLR-induced IPSC suppression was more prominent in the neurons filled with the $\mathrm{pCa}$ 6 solution (Fig. 3E). Thus, the thapsigargin-sensitive component of IPSC suppression is likely to include a neuronal PAR1-dependent component. Together, we concluded that a large component, if not all, of 2-AG release was gliotransmitter-independent and neuronal PAR1-dependent.

\section{Discussion}

In this study, we have shown, for the first time, that activation of neuronal PAR1 triggers retrograde 2-AG signaling. This PAR1driven 2-AG signaling leads to suppression of inhibitory synaptic transmission through presynaptic $\mathrm{CB}_{1}$ receptors in hippocampal neurons. Because PAR1 and $\mathrm{CB}_{1}$ are distributed widely in the brain, this PAR1-CB 1 coupling is likely to be functional and to contribute to synaptic modulation throughout the brain, simi- 
larly to other endocannabinoid-producing receptors including glutamate (I-mGluR), acetylcholine $\left(\mathrm{M}_{1} / \mathrm{M}_{3}\right)$, serotonin (5$\mathrm{HT}_{2}$ ), oxytocin, orexin, and glucocorticoid receptors (Maejima et al., 2001; Kim et al., 2002; Haj-Dahmane and Shen, 2005; Best and Regehr, 2008; Kano et al., 2009).

Our results are supported by previous biochemical, anatomi$\mathrm{cal}$, and $\mathrm{Ca}^{2+}$-imaging studies. A biochemical study showed effects of thrombin on endocannabinoid levels in dorsal root ganglia (DRG) neurons (Vellani et al., 2008). The treatment of rat cultured DRG neurons with $100 \mathrm{~nm}$ thrombin elevated the levels of two major endocannabinoids, anandamide and 2-AG. The authors proposed a model in which PAR-PLC $\beta$-DGL $\alpha$ pathways mediate thrombin-induced $2-A G$ production. It has been reported that rat cultured hippocampal neurons exhibit PAR1immnoreactivtiy and expression of mRNA (Gorbacheva et al., 2009). Furthermore, the study using $\mathrm{Ca}^{2+}$-imaging has demonstrated the presence of functional PAR1 in cultured hippocampal neurons (Bushell et al., 2006). Because neuronal PAR1 expression has been also reported in brain slices (Weinstein et al., 1995; Niclou et al., 1998), we expect that neuronal PAR1-driven 2-AG signaling is functional also in vivo. However, cultured neurons could be different from the neurons in vivo in some aspects and we cannot exclude the possibility that PAR1 is upregulated under culture conditions. Further studies with slice preparations are necessary to understand the physiological significance of the PAR1-driven 2-AG signaling.

Previous studies with hippocampal slices demonstrated that PAR1 activation positively regulates neuronal excitatory synaptic activity (Gingrich et al., 2000; Lee et al., 2007; Maggio et al., 2008; Mannaioni et al., 2008). To the best of our knowledge, there are no studies reporting PAR1-induced suppression of excitatory transmission. Considering that hippocampal excitatory transmission is much less sensitive to cannabinoids (Ohno-Shosaku et al., 2002), it is possible that 2-AG signaling triggered by PAR1 activation is too weak to cause a detectable change in the excitatory transmission. We showed that PAR1-driven 2-AG signaling was independent of I-mGluR, indicating that PAR1-induced glutamate release from astrocytes (Lee et al., 2007) contributes little to 2-AG generation. The amount of glutamate released from astrocytes might be too small to trigger 2-AG synthesis in neurons. It is also possible that glia-neuron crosstalk was disconnected in our culture preparations, although a previous study clearly demonstrated that the crosstalk was intact even in culture (Lee et al., 2007).

In the hippocampus, PAR1 activators could exert opposite actions on excitatory and inhibitory synaptic transmissions. The potentiation of excitation is mediated by astrocytic PAR1 and gliotransmitters (Lee et al., 2007; Mannaioni et al., 2008), and the suppression of inhibition is mediated by neuronal PAR1 and endocannabinoids. If these two pathways are driven simultaneously, the excitatory signal is synergistically potentiated and LTP induction may be facilitated. The finding that PAR1 triggers 2-AG signaling provides a new insight into the roles of PAR1 under not only physiological but also pathological conditions. The endocannabinoid system has also been reported to be associated with neurodegeneration and neuroprotection (Fowler et al., 2010). It will be of great interest to investigate whether PAR1driven 2-AG signaling contributes to the previously reported roles of PAR1 in the CNS.

\section{References}

Alger BE (2002) Retrograde signaling in the regulation of synaptic transmission: focus on endocannabinoids. Prog Neurobiol 68:247-286.
Almonte AG, Hamill CE, Chhatwal JP, Wingo TS, Barber JA, Lyuboslavsky PN, David Sweatt J, Ressler KJ, White DA, Traynelis SF (2007) Learning and memory deficits in mice lacking protease activated receptor-1. Neurobiol Learn Mem 88:295-304.

Best AR, Regehr WG (2008) Serotonin evokes endocannabinoid release and retrogradely suppresses excitatory synapses. J Neurosci 28:6508-6515.

Bushell TJ, Plevin R, Cobb S, Irving AJ (2006) Characterization of proteinase-activated receptor 2 signalling and expression in rat hippocampal neurons and astrocytes. Neuropharmacology 50:714-725.

Connolly AJ, Ishihara H, Kahn ML, Farese RV Jr, Coughlin SR (1996) Role of the thrombin receptor in development and evidence for a second receptor. Nature 381:516-519.

Fowler CJ, Rojo ML, Rodriguez-Gaztelumendi A (2010) Modulation of the endocannabinoid system: neuroprotection or neurotoxicity? Exp Neurol 224:37-47.

Fujita T, Liu T, Nakatsuka T, Kumamoto E (2009) Proteinase-activated receptor- 1 activation presynaptically enhances spontaneous glutamatergic excitatory transmission in adult rat substantia gelatinosa neurons. J Neurophysiol 102:312-319.

Gao Y, Vasilyev DV, Goncalves MB, Howell FV, Hobbs C, Reisenberg M, Shen R, Zhang MY, Strassle BW, Lu P, Mark L, Piesla MJ, Deng K, Kouranova EV, Ring RH, Whiteside GT, Bates B, Walsh FS, Williams G, Pangalos MN, et al. (2010) Loss of retrograde endocannabinoid signaling and reduced adult neurogenesis in diacylglycerol lipase knock-out mice. J Neurosci 30:2017-2024.

Gingrich MB, Junge CE, Lyuboslavsky P, Traynelis SF (2000) Potentiation of NMDA receptor function by the serine protease thrombin. J Neurosci 20:4582-4595.

Gorbacheva L, Davidova O, Sokolova E, Ishiwata S, Pinelis V, Strukova S, Reiser G (2009) Endothelial protein C receptor is expressed in rat cortical and hippocampal neurons and is necessary for protective effect of activated protein $\mathrm{C}$ at glutamate excitotoxicity. J Neurochem 111:967-975.

Haj-Dahmane S, Shen RY (2005) The wake-promoting peptide orexin-B inhibits glutamatergic transmission to dorsal raphe nucleus serotonin neurons through retrograde endocannabinoid signaling. J Neurosci 25:896-905.

Hashimotodani Y, Ohno-Shosaku T, Tsubokawa H, Ogata H, Emoto K, Maejima T, Araishi K, Shin HS, Kano M (2005) Phospholipase C $\beta$ serves as a coincidence detector through its $\mathrm{Ca}^{2+}$ dependency for triggering retrograde endocannabinoid signal. Neuron 45:257-268.

Hashimotodani Y, Ohno-Shosaku T, Kano M (2007a) Endocannabinoids and synaptic function in the CNS. Neuroscientist 13:127-137.

Hashimotodani Y, Ohno-Shosaku T, Kano M (2007b) Presynaptic monoacylglycerol lipase activity determines basal endocannabinoid tone and terminates retrograde endocannabinoid signaling in the hippocampus. J Neurosci 27:1211-1219.

Hashimotodani Y, Ohno-Shosaku T, Maejima T, Fukami K, Kano M (2008) Pharmacological evidence for the involvement of diacylglycerol lipase in depolarization-induced endocanabinoid release. Neuropharmacology 54:58-67.

Heifets BD, Castillo PE (2009) Endocannabinoid signaling and long-term synaptic plasticity. Annu Rev Physiol 71:283-306.

Kano M, Ohno-Shosaku T, Hashimotodani Y, Uchigashima M, Watanabe M (2009) Endocannabinoid-mediated control of synaptic transmission. Physiol Rev 89:309-380.

Kawabata A, Saifeddine M, Al-Ani B, Leblond L, Hollenberg MD (1999) Evaluation of proteinase-activated receptor-1 (PAR1) agonists and antagonists using a cultured cell receptor desensitization assay: activation of PAR2 by PAR1-targeted ligands. J Pharmacol Exp Ther 288:358 -370.

Kim J, Isokawa M, Ledent C, Alger BE (2002) Activation of muscarinic acetylcholine receptors enhances the release of endogenous cannabinoids in the hippocampus. J Neurosci 22:10182-10191.

Kreitzer AC, Regehr WG (2001) Retrograde inhibition of presynaptic calcium influx by endogenous cannabinoids at excitatory synapses onto Purkinje cells. Neuron 29:717-727.

Lee CJ, Mannaioni G, Yuan H, Woo DH, Gingrich MB, Traynelis SF (2007) Astrocytic control of synaptic NMDA receptors. J Physiol 581:1057-1081.

Luo W, Wang Y, Reiser G (2007) Protease-activated receptors in the brain: receptor expression, activation, and functions in neurodegeneration and neuroprotection. Brain Res Rev 56:331-345.

Maejima T, Hashimoto K, Yoshida T, Aiba A, Kano M (2001) Presynaptic 
inhibition caused by retrograde signal from metabotropic glutamate to cannabinoid receptors. Neuron 31:463-475.

Maejima T, Oka S, Hashimotodani Y, Ohno-Shosaku T, Aiba A, Wu D, Waku K, Sugiura T, Kano M (2005) Synaptically driven endocannabinoid release requires $\mathrm{Ca}^{2+}$-assisted metabotropic glutamate receptor subtype 1 to phospholipase $\mathrm{C} \beta 4$ signaling cascade in the cerebellum. J Neurosci 25:6826-6835.

Maggio N, Shavit E, Chapman J, Segal M (2008) Thrombin induces long-term potentiation of reactivity to afferent stimulation and facilitates epileptic seizures in rat hippocampal slices: toward understanding the functional consequences of cerebrovascular insults. J Neurosci 28:732-736.

Mannaioni G, Orr AG, Hamill CE, Yuan H, Pedone KH, McCoy KL, Berlinguer Palmini R, Junge CE, Lee CJ, Yepes M, Hepler JR, Traynelis SF (2008) Plasmin potentiates synaptic $N$-methyl-D-aspartate receptor function in hippocampal neurons through activation of proteaseactivated receptor-1. J Biol Chem 283:20600-20611.

McLaughlin JN, Shen L, Holinstat M, Brooks JD, Dibenedetto E, Hamm HE (2005) Functional selectivity of $\mathrm{G}$ protein signaling by agonist peptides and thrombin for the protease-activated receptor-1. J Biol Chem 280:25048-25059.

Mothet JP, Pollegioni L, Ouanounou G, Martineau M, Fossier P, Baux G (2005) Glutamate receptor activation triggers a calcium-dependent and SNARE protein-dependent release of the gliotransmitter D-serine. Proc Natl Acad Sci U S A 102:5606-5611.

Nagai T, Ito M, Nakamichi N, Mizoguchi H, Kamei H, Fukakusa A, Nabeshima T, Takuma K, Yamada K (2006) The rewards of nicotine: regulation by tissue plasminogen activator-plasmin system through protease activated receptor-1. J Neurosci 26:12374-12383.

Niclou SP, Suidan HS, Pavlik A, Vejsada R, Monard D (1998) Changes in the expression of protease-activated receptor 1 and protease nexin-1 mRNA during rat nervous system development and after nerve lesion. Eur J Neurosci 10:1590-1607.
Ohno-Shosaku T, Maejima T, Kano M (2001) Endogenous cannabinoids mediate retrograde signals from depolarized postsynaptic neurons to presynaptic terminals. Neuron 29:729-738.

Ohno-Shosaku T, Tsubokawa H, Mizushima I, Yoneda N, Zimmer A, Kano M (2002) Presynaptic cannabinoid sensitivity is a major determinant of depolarization-induced retrograde suppression at hippocampal synapses. J Neurosci 22:3864-3872.

Ossovskaya VS, Bunnett NW (2004) Protease-activated receptors: contribution to physiology and disease. Physiol Rev 84:579-621.

Perea G, Navarrete M, Araque A (2009) Tripartite synapses: astrocytes process and control synaptic information. Trends Neurosci 32:421-431.

Shigetomi E, Bowser DN, Sofroniew MV, Khakh BS (2008) Two forms of astrocyte calcium excitability have distinct effects on NMDA receptormediated slow inward currents in pyramidal neurons. J Neurosci 28:6659-6663.

Tanimura A, Yamazaki M, Hashimotodani Y, Uchigashima M, Kawata S, Abe M, Kita Y, Hashimoto K, Shimizu T, Watanabe M, Sakimura K, Kano M (2010) The endocannabinoid 2-arachidonoylglycerol produced by diacylglycerol lipase $\alpha$ mediates retrograde suppression of synaptic transmission. Neuron 65:320-327.

Vellani V, Petrosino S, De Petrocellis L, Valenti M, Prandini M, Magherini PC, McNaughton PA, Di Marzo V (2008) Functional lipidomics: calcium-independent activation of endocannabinoid/endovanilloid lipid signalling in sensory neurons by protein kinases $\mathrm{C}$ and $\mathrm{A}$ and thrombin. Neuropharmacology 55:1274-1279.

Weinstein JR, Gold SJ, Cunningham DD, Gall CM (1995) Cellular localization of thrombin receptor mRNA in rat brain: expression by mesencephalic dopaminergic neurons and codistribution with prothrombin mRNA. J Neurosci 15:2906-2919.

Wilson RI, Nicoll RA (2001) Endogenous cannabinoids mediate retrograde signalling at hippocampal synapses. Nature 410:588-592. 